\title{
Quantificação e controle de enterobactérias e coliformes totais na produção de sucos e polpas de frutas industrializados
}

\author{
Félix Giovani Ramos Guerrero, Rosane da Silva Rodrigues
}

https://doi.org/10.4322/mp.978-65-991393-5-2.c7

\section{Resumo}

Apesar das indústrias possuírem basicamente o mesmo fluxograma para obter sucos/polpas de frutas, as características de processo podem variar em termos microbiológicos. Visando assegurar que as operações de uma fábrica processadora de frutas sejam eficientes em controlar as cargas microbiológicas que podem afetar 0 produto final, o objetivo deste estudo foi quantificar a carga de enterobactérias e de coliformes totais em polpa de morango (PM) e em suco de maracujá (SM) sem pasteurizar, determinando a melhor distribuição de probabilidade que explique seu comportamento, e também fazer um comparativo com a carga microbiana restante após o processo de pasteurização, aplicado num processo industrial, comprovando a eficiência do tratamento térmico na inativação desses micro-organismos. Assim, foram verificadas as contagens que excederam os 5 Log UFC $g^{-1}$, valor padrão de importância em segurança alimentar nos sucos de frutas industrializados. Os resultados mostraram que a PM e o SM não diferiram nas contagens microbiológicas, mas o comportamento entre lotes de cada produto foi muito diferente, e se adequaram melhor às distribuições de Laplace (coliformes totais em PM e enterobactérias em SM), Normal (enterobactérias em PM) e ExtValueMin (coliformes totais em SM) segundo os critérios estatísticos avaliados (Qui-Quadrado, Critério de Informação Akaike e Critério de Informação Bayesiano). Apesar de ocorrem contagens superiores a 5 Log UFC $g^{-1}$ de enterobactérias e coliformes totais na PM e no SM, a

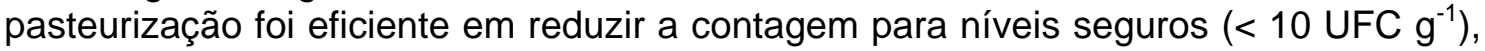
evidenciando que estes grupos de micro-organismos podem ser considerados indicadores nos produtos avaliados.

Palavras-chave: maracujá, micro-organismos indicadores, morango, tratamento térmico.

\section{Introdução}

Sucos e polpas de frutas congelados são produzidos industrialmente com a finalidade de poder preservá-los e comercializá-los, disponibilizando aos consumidores de mercados nacionais e internacionais acesso a produtos com sabores e aromas característicos de frutas nativas de diferentes regiões. A expansão de mercado possibilita o desenvolvimento das áreas agrícolas onde são cultivadas essas frutas e a melhoria das condições de vida para os agricultores e demais setores envolvidos na cadeia produtiva (RODRIGUES; RIBEIRO; da SILVA, 2015).

A fabricação de sucos e polpas de frutas em nível industrial passa por diferentes etapas de processos, dentre os quais destacam-se a sanitização e a pasteurização, 
capazes de reduzir a níveis seguros a carga de micro-organismos patogênicos e deteriorantes (PARAMITHIOTIS; DROSINOS; SKANDAMIS, 2017). Apesar do surgimento de diversas tecnologias não térmicas de conservação, como a alta pressão hidrostática, ultrassom, plasma a frio, campos elétricos pulsados, luz pulsada, entre outros, em muitos países a pasteurização ainda segue sendo o principal método de conservação utilizado pela maioria dos processadores de frutas, devido, principalmente, ao fato de que algumas dessas novas tecnologias atualmente estão desenhadas para embalagens em pequenos volumes (menores do que $20 \mathrm{~kg}$ ) e por que alguns desses processos só são efetivos quando combinados com outros métodos, como por exemplo com antimicrobianos ou com tratamentos térmicos brandos (BEVILACQUA et al., 2018). As tecnologias não térmicas apresentam muitas vantagens frente à pasteurização, preservando mais as características sensoriais e nutricionais do produto final, e seu uso vem aumentando na produção de sucos de frutas prontos-para-beber (comercializados principalmente em mercados e supermercados); no entanto, ainda apresentam limitações, sobretudo no processamento de grandes volumes na produção de sucos e polpas de frutas destinados a serem matérias-primas/insumos de outras indústrias (comercializados entre empresas), cujas apresentações são comumente em embalagens maiores do que 200 kg (ORELLANA et al., 2017; BEVILACQUA et al., 2018).

Para poder desenvolver um adequado controle nas operações de processo de alimentos e bebidas, e reduzir a probabilidade de deterioração ou de risco à segurança dos consumidores, é preciso conhecer profundamente as características e peculiaridades dos processos em cada indústria. A quantificação microbiana e sua distribuição no alimento é de suma importância no controle de qualidade, por representar a variabilidade intrínseca do processo e permitir colocar barreiras para controlá-las (KILSBY; PUGH, 1981).

Devido aos elevados riscos de contaminação (biossegurança) e aos baixos níveis de ocorrência no produto (prevalência), os laboratórios das indústrias processadoras de frutas comumente não realizam análises de micro-organismos patogênicos, substituindo-as por análises de micro-organismos indicadores (BAYLIS et al., 2011). Dentre estes grupos de micro-organismos indicadores destacam-se as enterobactérias e os coliformes totais, os quais fornecem informação à área de garantia de qualidade acerca das boas ou más condições higiénico-sanitárias durante o processamento, sendo sua presença de relevância particularmente em produtos pasteurizados (FRANCO; LANDGRAF, 2008; BAYLIS et al., 2011).

Os surtos de doenças ocasionadas por sucos de laranja ou de maçã não pasteurizados e contaminados com Salmonella enteritidis ou Escherichia coli O157:H7 (VOJDANI; BEUCHAT; TAUXE, 2008; TRIBST; SANT'ANA; MASSAGUER, 2009) têm demonstrado que os sucos de frutas (incluindo os que apresentam $\mathrm{pH}<4.6$ ) são potencialmente perigosos (SALOMÃO, 2018), o que justifica a preocupação com esta categoria de produtos. Uma das formas de garantir a inocuidade dos sucos de frutas é o processamento, onde pelo menos uma etapa deve possibilitar a redução de no mínimo 5 ciclos logarítmicos (5 Log) sob um micro-organismo patogênico de importância para a saúde pública e cuja presença seja provável no suco (U.S. FOOD AND DRUG ADMINISTRATION, 2004). Salmonella enteritidis e Escherichia coli O157:H7 são bactérias patogênicas "alvos" usadas para verificar o cumprimento desta premissa e elas pertencem aos grupos de micro-organismos indicadores de enterobactérias e coliformes, respectivamente (BAYLIS, 2006).

Algumas pesquisas estabelecem que a carga de micro-organismos indicadores não tem relação direta com a carga de uma bactéria patogênica específica presente nos 
alimentos mesmo que ela pertença ao grupo do micro-organismo indicador avaliado (MISKIMIN et al., 1976; MERCURI et al., 1978). Contudo, quando se verifica ausência de enterobactérias a probabilidade de Salmonella sp. estar presente no alimento diminui; e, baseados nesse critério, é possível predizer a ausência deste microorganismo patogênico quando não se apresentam contagens do micro-organismo indicador sempre que a bactéria patogênica pertença a este grupo e que se tenha em conta a sensibilidade do método de análise (RUBY; INGHAM, 2009).

Com a finalidade de contribuir ao conhecimento da microbiologia de sucos/polpas de frutas quando processadas em nível industrial, esta pesquisa teve como objetivos: i) quantificar a carga de enterobactérias e coliformes totais em polpa de morango e em suco de maracujá sem pasteurizar, verificando a melhor distribuição de probabilidade que explica seu comportamento e determinando a percentagem de valores que excedem uma contagem de 5 Log UFC $\mathrm{g}^{-1}$, e ii) quantificar a carga de enterobactérias e coliformes totais em polpa de morango e em suco de maracujá após pasteurização, comparando-as com a carga microbiológica obtida antes do tratamento térmico para verificar sua eficiência na inativação desses grupos de micro-organismos.

\section{Materiais e Métodos}

\subsection{Processo de obtenção de sucos/polpas de frutas a nível industrial}

Polpa de morango (Fragaria vesca L.) e suco de maracujá (Passiflora edulis var. flavicarpa) produzidos em nível industrial, num processo contínuo de produção, em Callao (Peru) foram usados neste estudo, sendo as matérias-primas (fruta) de origem peruana. A polpa de morango foi obtida seguindo as etapas de processo: recepção/armazenamento da fruta, pesagem, seleção e retirada do cálice, desinfecção, enxágue, seleção, despolpamento, refino, homogeneização, pasteurização (80 ${ }^{\circ} \mathrm{C} / 69$ seg.), resfriamento, filtração, envase e congelamento. Por outro lado, o processamento do suco de maracujá seguiu as etapas de recepção/armazenamento da fruta, pesagem, pré-lavagem, seleção, escovamento/desinfecção, escovamento/enxágue, seleção, ruptura da casca, centrifugação, refino, homogeneização, pasteurização $\left(85^{\circ} \mathrm{C} / 103\right.$ seg.), resfriamento, filtração, envase e congelamento.

Apesar da indústria onde foram obtidas as amostras de polpa de morango e suco de maracujá também processar polpa de manga e polpa de camu-camu, essas polpas não foram consideradas para este estudo devido ao fato que elas apresentam uma carga microbiológica muito baixa antes da pasteurização por receberem durante seu processamento um tratamento térmico (branqueamento ou chapoteo) prévio à homogeneização.

\subsection{Coleta de amostras durante a produção}

Em ambos os processos (polpa de morango e suco de maracujá), os pontos de amostragem foram a etapa de "homogeneização" para extração de polpa/suco sem pasteurizar e a etapa de "pasteurização", em que foi obtida a polpa/suco com tratamento térmico. Em cada ponto foi extraída assepticamente $500 \mathrm{~g}$ de suco/polpa, a qual foi mantida sob refrigeração e transportada imediatamente ao laboratório da fábrica para análise. Em cada ponto de amostragem foram coletadas 30 amostras, as quais pertenciam a diferentes lotes de fabricação, tanto de polpa de morango como de suco de maracujá. Dentro do processo de fabricação de polpa/sucos de frutas nesta indústria, um lote equivale a $1600 \mathrm{~kg}$ de produto homogeneizado. 


\subsection{Análises físico-químicas e microbiológicas}

Polpa de morango e suco de maracujá foram caracterizados físico-quimicamente através da determinação de sólidos solúveis totais ( $\left.{ }^{\circ} B r i x\right)$, acidez titulável (expressa em percentagem de ácido cítrico) e $\mathrm{pH}$, de acordo às metodologias preconizadas pelo ISO 2173 (2003), ISO 750 (1998) e ISO 1842 (1991), respectivamente.

Análises microbiológicas de enterobactérias e de coliformes totais foram realizadas em todas as amostras de polpa de morango $(n=60)$ e de suco de maracujá $(n=60)$. Para a avaliação de enterobactérias foi usado o método indicado na ISO 21528-2 (2004) enquanto que o método estabelecido pela American Public Health Association foi usado para a quantificação de coliformes totais (KORNACKI; JOHNSON, 2001).

\subsection{Ajuste das contagens microbiológicas às distribuições estatísticas de probabilidade}

As contagens microbiológicas de enterobactérias e coliformes totais foram expressas em Log UFC $g^{-1}$ e ajustadas às distribuições estatísticas de probabilidade (DEP) usando o software @RISK Versão 7.5.1 (Palidase Corporation, NY, USA), desenvolvido através de uma interface de análise de risco para o Microsoft Excel. $O$ teste de adequação do ajuste (goodness-of-fit) foi realizado através do método de QuiQuadrado, do Critério de Informação Akaike (AIC) e do Critério de Informação Bayesiano (BIC).

\subsection{Estimação quantitativa da variabilidade das contagens microbiológicas}

Com ajuda do software @RISK Versão 7.5.1 (Palidase Corporation, NY, USA), simulações de Monte Carlo (100 000 iterações) foram realizadas para determinar a variabilidade das contagens microbiológicas em cada distribuição que melhor ajustou os dados. Em cada grupo de micro-organismos a percentagem de contagens que foram superiores a 5 ciclos logarítmicos ( 5 Log) UFC $g^{-1}$ foi determinada mediante 0 uso de cada distribuição.

\subsection{Quantificação da inativação de micro-organismos indicadores}

O diagrama de caixas foi desenvolvido para observar graficamente a diferença que existe entre as contagens microbiológicas antes e após pasteurização em cada grupo de micro-organismos, tanto para a polpa de morango como para o suco de maracujá.

\section{Resultados e Discussão}

A maioria das bactérias patogênicas são inibidas pelo $\mathrm{pH}$ ácido da polpa/suco de fruta (<4.6); no entanto, algumas são capazes de adaptar-se e sobreviver neste ambiente (OYARZÁBAL; NOGEURIA; GOMBAS, 2003; STRAWN; SCHNEIDER; DANYLUK, 2011). Os valores de $\mathrm{pH}$ que apresenta um suco/polpa de fruta é o resultado principalmente do equilíbrio entre os ácidos presentes, como o cítrico, tartárico, málico, entre outros (COTON; LEGUERINEL, 2014). Neste estudo, ambos os produtos apresentaram um pH menor do que 3,47 (Tabela 1), sendo o suco de maracujá (SM) o mais ácido dentre deles ( $\mathrm{pH}: 2,95)$, estando em concordância com o maior valor obtido para o parâmetro de acidez titulável (394,8\% mais do que a polpa de morango).

A concentração de sólidos solúveis totais ( ${ }^{\circ}$ Brix) no alimento pode influenciar no desenvolvimento dos micro-organismos (fonte de energia) e pode exercer um efeito protetor frente a tratamentos de inativação, podendo aumentar sua resistência 
(SLONGO; MIORELLI; ARAGÃO, 2005; GOH et al., 2007). Neste caso, o SM apresentou $84.3 \%$ mais sólidos solúveis totais do que a polpa de morango (PM).

Tabela 1. Características físico-químicas dos sucos/polpas $(n=30)$ sem pasteurizar.

\begin{tabular}{crcc}
\hline Produto & SST & ATT & pH \\
\hline Polpa de Morango & $6,95 \pm 0,41$ & $0,77 \pm 0,05$ & $3,47 \pm 0,06$ \\
Suco de Maracujá & $12,81 \pm 0,44$ & $3,81 \pm 0,24$ & $2,95 \pm 0,05$ \\
\hline
\end{tabular}

SST: sólidos solúveis totais em ${ }^{\circ}$ Brix; ATT: acidez total titulável em \% ácido cítrico.

Algumas cepas de enterobactérias podem tolerar $\mathrm{pH}$ menores do que 4,0 , como do SM e PM, e geralmente não são resistentes ao calor, aspectos que as qualificam como potenciais micro-organismos indicadores para alimentos tratados termicamente (BAYLIS, 2006). Essa informação é relevante considerando as características intrínsecas dos produtos avaliados, as quais podem gerar uma barreira para o desenvolvimento de enterobactérias e coliformes totais e também influenciar na sua sobrevivência e inativação, podendo afetar sua carga microbiológica.

Para entender todas as trocas que ocorrem normalmente na microbiota dentro de um alimento durante seu processo de fabricação e identificar qual etapa é mais importante do ponto de vista microbiológico, é necessário determinar e quantificar os microorganismos presentes (KILSBY; PUGH, 1981). As contagens microbiológicas dos lotes de polpas/sucos industrializados sem pasteurizar e sem transformação (UFC g $^{-1}$ ) são mostrados na Figura 1. O comportamento das enterobactérias em PM e SM e os coliformes em PM são muito similares, apresentando valores regulares com picos (maior contagem) em alguns casos.

Comportamento flutuante e irregular foi evidenciado para as contagens de coliformes totais em SM. Esse comportamento é muito comum dentro de registros de contagens microbiológicas industriais em diversos produtos (PELEG, 2002; CORRADINI et al., 2002) e ocorre devido às variações na carga inicial e à interação de diversos fatores inerentes ao processo produtivo que podem exercer alguma influência sob 0 crescimento ou morte nos micro-organismos. Enquanto fatores como os intervalos de sanitização (cada 12 horas nesta indústria) e seu procedimento CIP (Cleaning-in-Place de 7 etapas de processo: enxágue, limpeza alcalina, enxágue, limpeza ácida, enxágue, sanitização e enxágue final) não mudarem drasticamente, esse comportamento não mudará (CORRADINI et al., 2001).

Baseados nos métodos do Qui-Quadrado, do Critério de Informação Akaike (AIC) e do Critério de Informação Bayesiano (BIC), conhecidos também como medidas de bondade de ajuste, as contagens de enterobactérias em PM e em SM se ajustam melhor a uma DEP Normal e Laplace, respectivamente. Por outro lado, as cargas microbiológicas de coliformes totais em PM e em SM apresentaram melhor ajuste às DEP Laplace e ExtValueMin (Tabela 2). Quanto menor sejam os valores do QuiQuadrado, AIC e BIC, melhores são as adaptações das contagens microbiológicas ao DEP avaliado. É importante ressaltar que apesar das contagens microbiológicas se adequaram melhor a determinadas DEP (baseados em métodos estatísticos), um estudo realizado por Corradini et al. (2001) em três produtos comerciais industrializados (leite cru, concentrado de maçã congelado e um snack baseado num produto lácteo) determinou que nenhuma dessas distribuições se destacou para descrever o comportamento de aeróbios mesófilos, leveduras e micro-organismos anaeróbios e termófilos e predizer contagens que excederam um limite estabelecido. 
COLIFORMES TOTAIS

ENTEROBACTÉRIAS

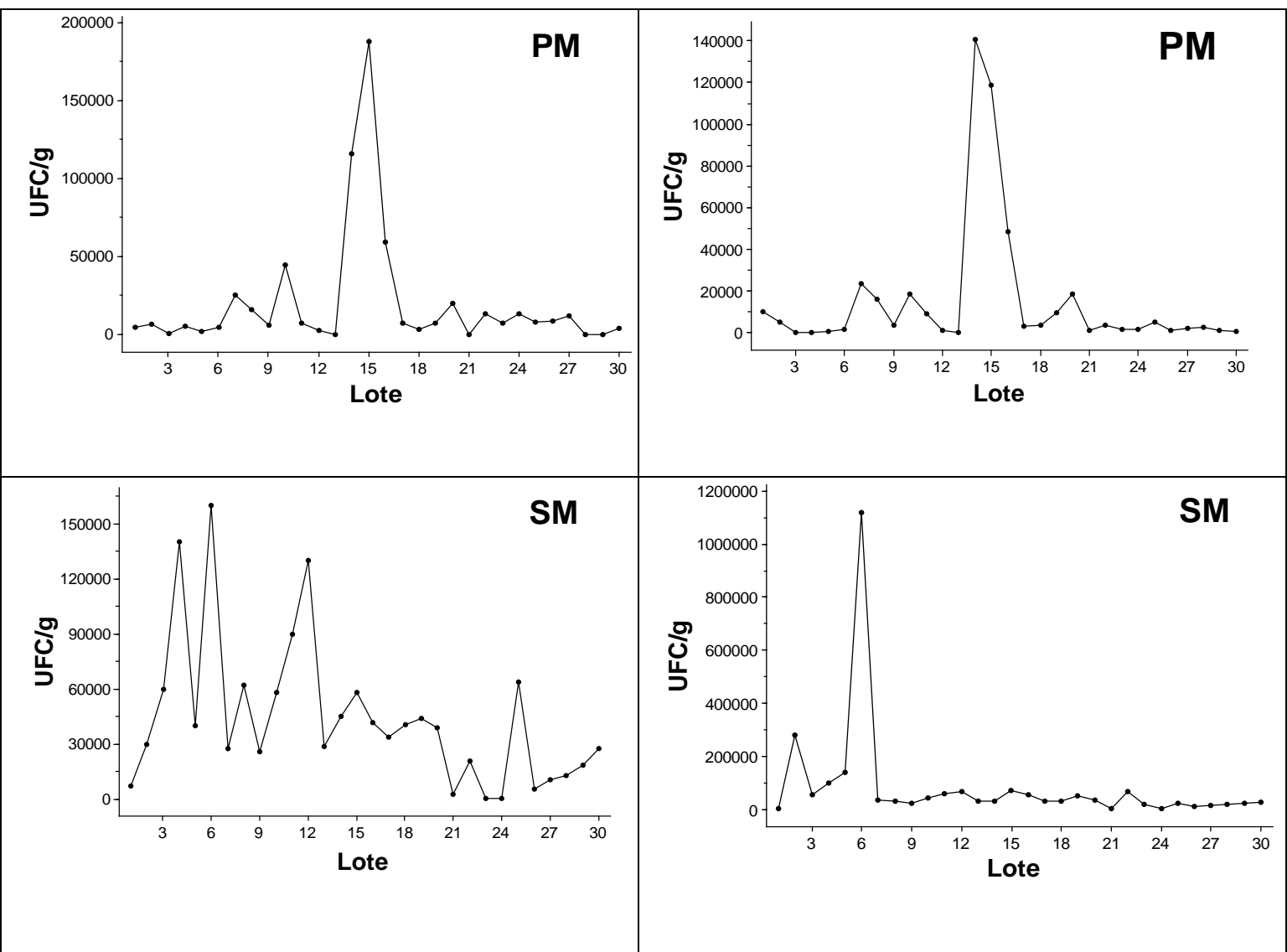

Figura 1. Série de contagens microbiológicas de coliformes totais e de enterobactérias em lotes $(n=30)$ de polpa de morango $(P M)$ e de suco de maracujá (SM) não pasteurizados.

Tabela 2. Médias e medidas de bondade de ajuste das contagens de enterobactérias (E) e coliformes totais (CT) em polpa de morango (PM) e em suco de maracujá (SM) sem pasteurizar frente aos tipos de distribuição estatística de probabilidade.

\begin{tabular}{|c|c|c|c|c|c|c|}
\hline \multirow[b]{2}{*}{ Produto } & \multirow{2}{*}{$\begin{array}{c}\text { Grupo de } \\
\text { micro- } \\
\text { organismo }\end{array}$} & \multirow{2}{*}{$\begin{array}{c}\text { Tipo de } \\
\text { distribuição }\end{array}$} & \multirow{2}{*}{$\begin{array}{c}\text { Média } \pm \\
\text { desvio padrão } \\
\left(\log \text { UFC g }{ }^{-1}\right)\end{array}$} & \multicolumn{3}{|c|}{$\begin{array}{l}\text { Teste para determinar o } \\
\text { grau de semelhança* }\end{array}$} \\
\hline & & & & $\begin{array}{c}\text { Qui- } \\
\text { quadrado }\end{array}$ & AIC & BIC \\
\hline \multirow[t]{2}{*}{ PM } & CT & Laplace & $3,86 \pm 0,79$ & 0,800 & 71,276 & 73,634 \\
\hline & E & Normal & $3,52 \pm 0,80$ & 0,800 & 74,897 & 77,254 \\
\hline \multirow[t]{2}{*}{ SM } & CT & ExtValueMin & $4,42 \pm 0,52$ & 2,000 & 46,433 & 48,791 \\
\hline & $E$ & Laplace & $4,54 \pm 0,44$ & 2,400 & 35,807 & 38,165 \\
\hline
\end{tabular}

* Medida quantitativa do grau de semelhança da distribuição dos dados ajustados com a distribuição ajustada. AIC: Critério de informação de Akaike; BIC: Critério de informação bayesiano.

Uma distribuição Laplace é usada quando a distribuição de dados apresenta mais picos do que uma distribuição normal e quando os dados têm caudas longas (ARYAL, 
2006). Isso é concordante com as características dos dados de coliformes totais em $\mathrm{PM}$ e enterobactérias em SM. As contagens de enterobactérias em polpa de morango apresentaram menos valores nas extremidades da curva de distribuição, sendo simétricas, o que a caracteriza como uma distribuição normal.

As DEP são usadas para descrever a contaminação microbiana nos alimentos e indicam o padrão estabelecido para os níveis de contaminação esperado quando amostras aleatorizadas são selecionadas dentro de um mesmo lote (FAO/WHO, 2016). A forma como os micro-organismos se encontram distribuídos no alimento determinará a probabilidade de causar uma enfermidade ou provocar deterioração, sendo esses dados muito importantes para a área de garantia de qualidade quando são necessárias informações para a tomada de decisões sobre a aceitação ou rejeição de um lote de produto ou aprovação de uma etapa de processo.

Nos alimentos, os micro-organismos encontram-se distribuídos fisicamente e os mecanismos como contaminação, crescimento e morte/inativação microbiana, agregação, mistura e fracionamento, podem influenciar marcadamente os tipos de distribuições espaciais que eles podem apresentar no produto final (JONGENBURGER et al., 2012). Esses mecanismos ocorrem através das diversas fases ou processos pelos quais atravessa um alimento, influenciando também sob seu nível final de contaminação (concentração ou percentagem de prevalência).

Baseado no descrito por Jongenburger et al. (2012), a Figura 2 apresenta os diferentes mecanismos que provavelmente tenham influência sob a dispersão dos micro-organismos durante um processamento típico de polpa de fruta congelada, tomando como exemplo a manufatura da polpa de morango, a qual pode ser estendida ao suco de maracujá.

\begin{tabular}{|c|c|c|c|}
\hline Localização & $\begin{array}{l}\text { Etapa de processo } \\
\text { sequencial }\end{array}$ & $\begin{array}{l}\text { Provável mecanismo } \\
\text { envolvido }\end{array}$ & $\begin{array}{l}\text { Fonte de contaminação } \\
\text { associada }\end{array}$ \\
\hline \multirow[t]{2}{*}{ 1. Campo } & Semeadura e cultivo & Contaminação & Água, ar, solo, animais \\
\hline & Colheita & Contaminação & Manipulador, solo \\
\hline \multirow[t]{8}{*}{ 2. Indústria $A$} & $\begin{array}{l}\text { Recepção I } \\
\text { Armazenamento }\end{array}$ & $\begin{array}{l}\text { Contaminação, } \\
\text { crescimento microbiano }\end{array}$ & $\begin{array}{l}\text { Ar, equipamento, outros lotes } \\
\text { de frutas }\end{array}$ \\
\hline & Pesagem & Contaminação & Equipamento \\
\hline & $\begin{array}{l}\text { Seleção e retirada do } \\
\text { cálice }\end{array}$ & $\begin{array}{l}\text { Agregação, } \\
\text { contaminação, } \\
\text { fracionamento }\end{array}$ & $\begin{array}{l}\text { Manipulador, utensílios de } \\
\text { corte }\end{array}$ \\
\hline & Desinfecção & $\begin{array}{l}\text { Agregação, morte } \\
\text { microbiana }\end{array}$ & Água clorada \\
\hline & Enxágue & $\begin{array}{l}\text { Agregação, } \\
\text { contaminação }\end{array}$ & Água potável \\
\hline & Seleção & $\begin{array}{l}\text { Agregação, } \\
\text { contaminação }\end{array}$ & $\begin{array}{l}\text { Manipulador, equipamentos } \\
\text { de transferência }\end{array}$ \\
\hline & Despolpamento & $\begin{array}{l}\text { Mistura, } \\
\text { contaminação }\end{array}$ & Equipamento \\
\hline & Refino & Contaminação & Equipamento \\
\hline
\end{tabular}




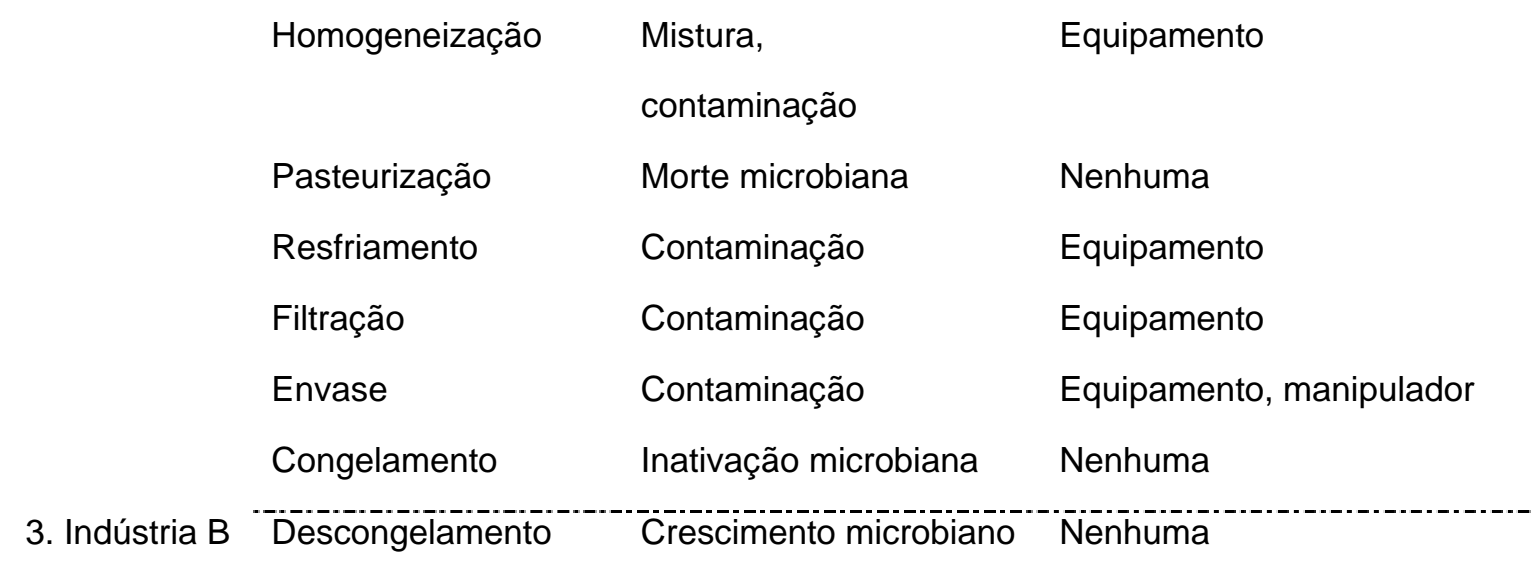

Figura 2. Prováveis mecanismos envolvidos no processamento de polpa de morango que influenciam na distribuição espacial final dos micro-organismos. Indústria $A$ : processadora de sucos/polpas de frutas congeladas; Indústria B: aquela que utiliza o suco/polpa de fruta como matéria-prima ou ingrediente para outros produtos. Adaptado de Jongenburger et al. (2012).

Em alimentos fluidos se espera que os micro-organismos se encontrem distribuídos mais uniformemente que em alimentos sólidos, contudo, também podem ocorrer casos de agrupamentos (clustering) os quais afetam diretamente na distribuição final das células microbianas. Além disso, é muito provável que cada amostra pertencente a um lote de produto homogêneo não tenha a mesma contagem microbiológica, considerando sua variabilidade intrínseca (JONGENBURGER et al., 2012).

A variação dos valores numa distribuição de frequências é chamada dispersão e é medida através da variância (expressada como o desvio padrão à potência 2), e quando existe uma sobre-dispersão na distribuição de frequências isso reflete num agrupamento na distribuição espacial. Uma simulação desta dispersão é mostrada nas Figuras 3 e 4, considerando 100000 iterações a partir dos dados iniciais de enterobactérias e coliformes totais em cada tipo de produto sem pasteurizar e o tipo de DEP previamente escolhido segundo a Tabela 2.

Nas Figuras 3 e 4 podem-se observar em detalhe as faixas das contagens microbiológicas e suas respectivas frequências. Valores superiores ao padrão estabelecido de 5 Log UFC $\mathrm{g}^{-1}$ de enterobactérias e coliformes totais foram encontrados em amostras não pasteurizadas provenientes dos dois produtos avaliados. De acordo com as distribuições estatísticas de probabilidade selecionadas em cada caso, 3,2\% (Fig. 3B) e 11,3\% (Fig. 4B) das amostras superaram as contagens de 5 Log UFC $\mathrm{g}^{-1}$ de enterobactérias em PM e SM, respectivamente, enquanto que $6,5 \%$ (Fig. 3A) e 9,7\% (Fig. 4A) dos valores obtidos em PM e SM apresentaram-se fora do padrão estabelecido neste estudo para coliformes totais. Apesar do seu baixo valor do $\mathrm{pH}$, o suco de maracujá foi o produto que apresentou os maiores valores fora do limite estabelecido (5 Log UFC ${ }^{-1}$ ) para ambos os grupos de micro-organismos indicadores. Isso assinala que os frutos utilizados nesses lotes de fabricação tiveram provavelmente maior contato com o solo e que as condições em que foram colhidos, armazenados e transportados até a fábrica não foram melhores do que aquelas empregadas para o morango. 


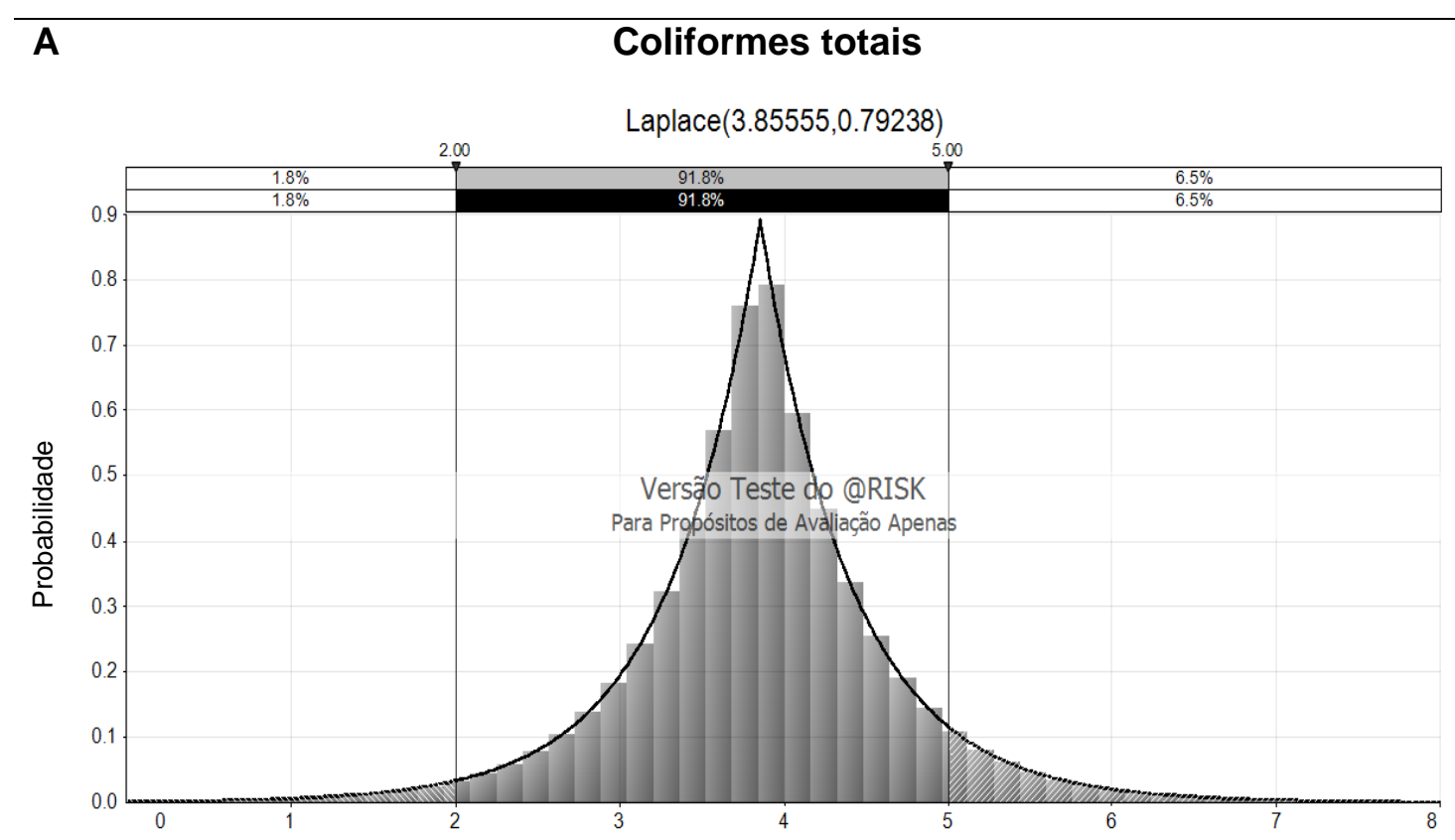

Log UFC/g

\section{B}

Enterobactérias

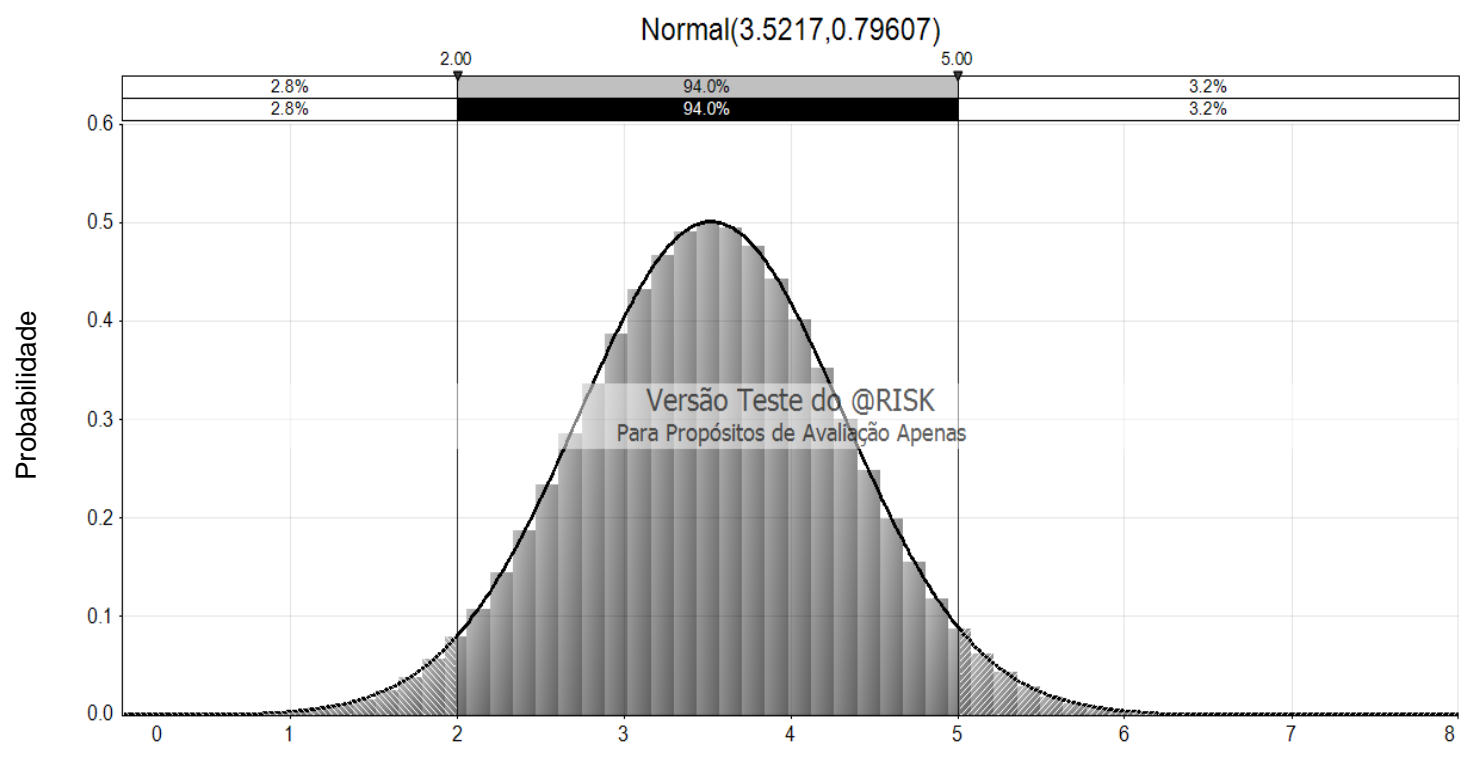

Log UFC/g

Figura 3. Uso da simulação de Monte Carlo (100 000 iterações) para a estimação quantitativa das contagens de coliformes totais (distribuição Laplace) e de enterobactérias (distribuição normal) em polpa de morango sem pasteurização. 


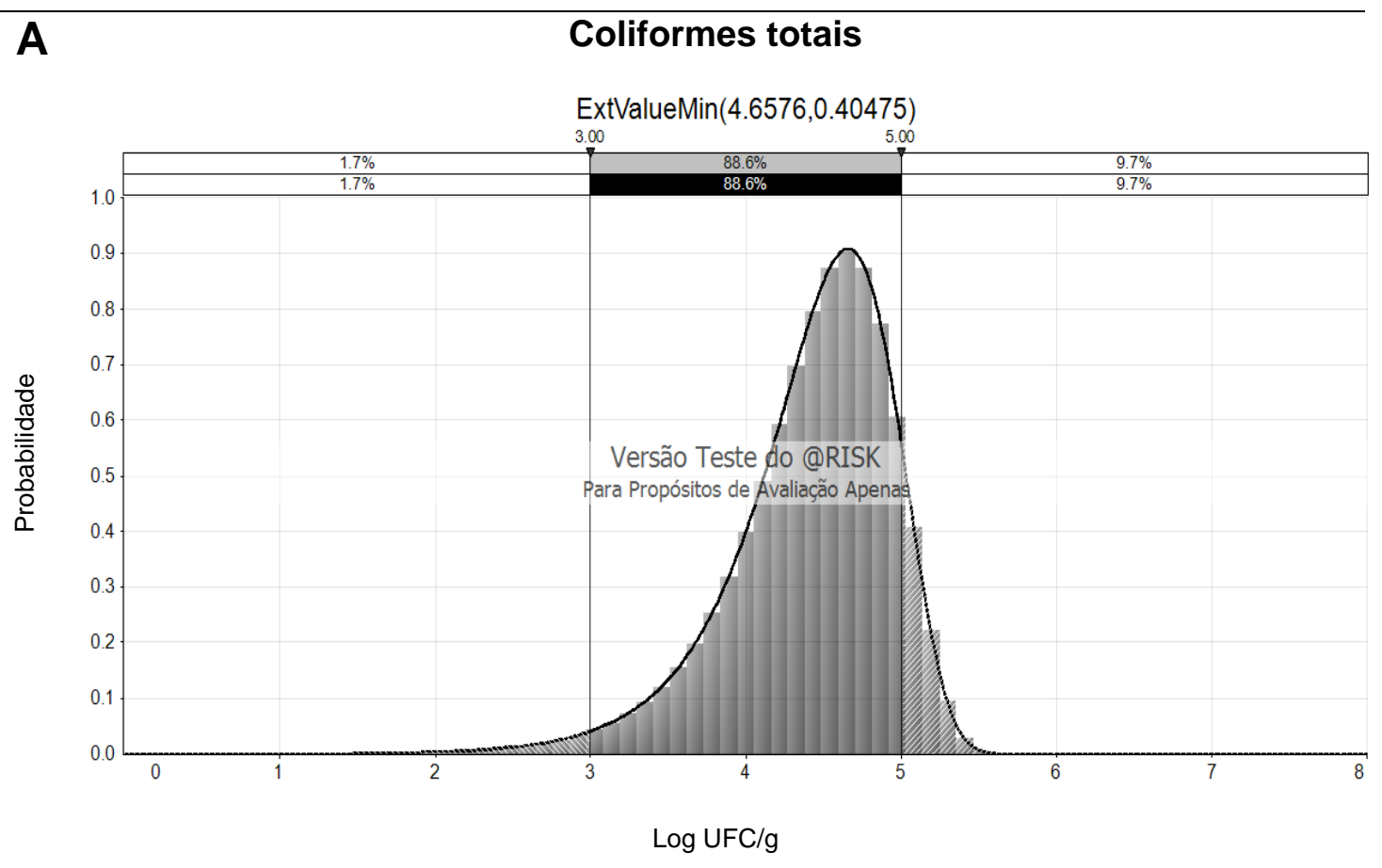

\section{B Enterobactérias}

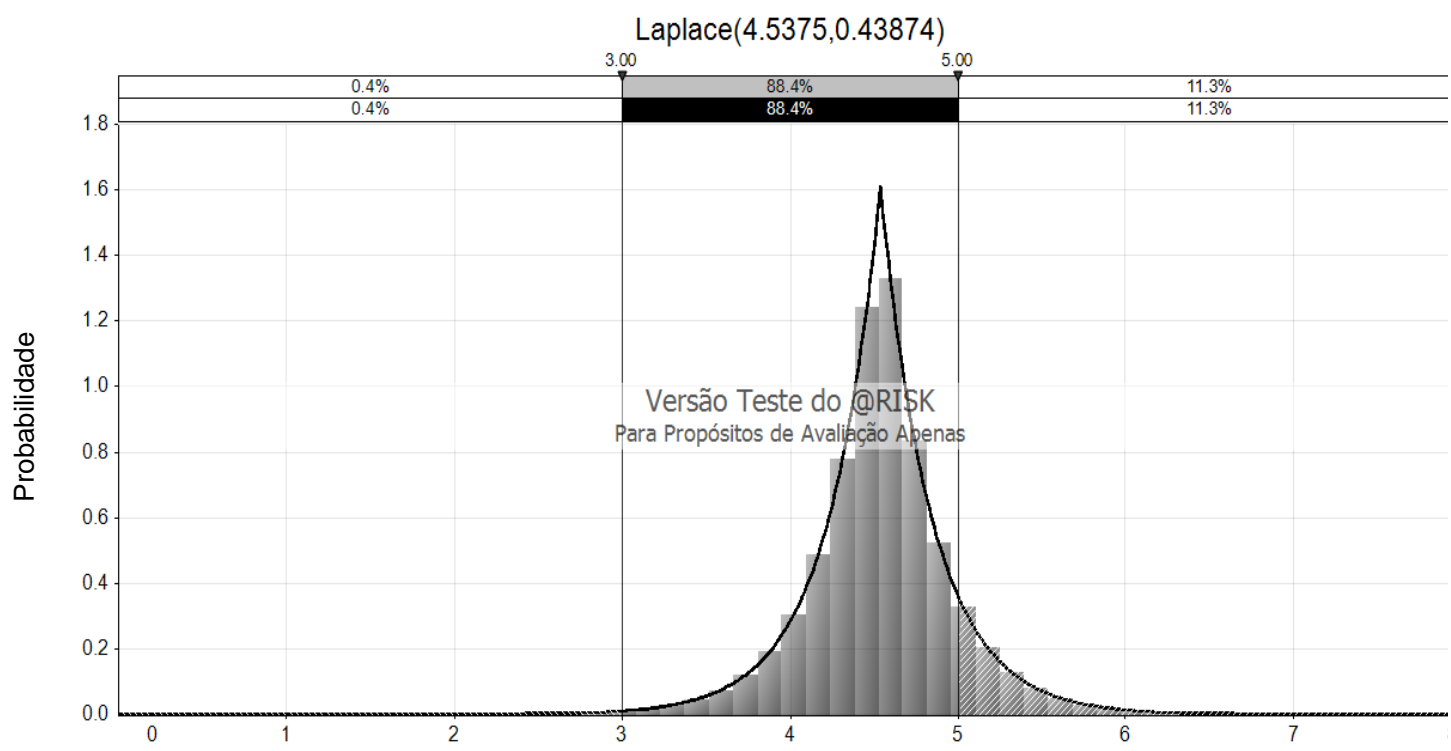

Log UFC/g

Figura 4. Estimação quantitativa das contagens de coliformes totais (distribuição ExtValueMin) e de enterobactérias (distribuição Laplace) em suco de maracujá sem pasteurização, mediante a aplicação da simulação de Monte Carlo (100 000 iterações).

Maracujazeiro e morangueiro são plantas com diferentes formas de cultivo no campo, o que influencia na microbiota dos seus frutos. O primeiro cresce em forma de videira (longe do solo), em regiões tropicais e subtropicais, sob temperaturas entre 20 a 32 ${ }^{\circ} \mathrm{C}$, sem ventos e geadas (CABRAL; FREIRE, MATTA, 2010), enquanto que 0 segundo tem mais probabilidade de ser contaminado por crescer perto do solo, 
podendo-se também contaminar com micro-organismos patogênicos pelas águas de irrigação. No entanto, estudos realizados em morangos provenientes de campos de cultivos na Bélgica e na Noruega indicaram ausência de Salmonella spp. e Escherichia coli produtora de toxina de Shiga (STEC), ressaltando a boa qualidade desses frutos e a forma adequada de cultivá-Ios (DELBEKE et al., 2015; JOHANNESSEN et al., 2015).

A contagem de coliformes pode ser usada como indicador de qualidade higiênicosanitária nas indústrias de alimentos. No estudo de Parish (1998) esta análise foi utilizada como informação microbiológica proveniente de amostras ambientais, de equipamentos e utensílios (transportadores de correias, filtros, drenos, pisos, luvas) de uma planta processadora de suco de laranja não pasteurizado envolvida num surto de salmonelose, ajudando a evidenciar que os procedimentos de limpeza e sanitização do equipamento, utensílios e ambiente de trabalho não foram adequados para prevenir a contaminação do suco engarrafado. Sem dúvida, nos últimos anos as contagens de coliformes estão sendo substituídos pelas de enterobactérias, sendo a preferida pelos fabricantes (BAYLIS et al., 2011).

Enterobactérias, além de ser um grupo de micro-organismos indicadores para boas práticas de fabricação, também são considerados importantes agentes deteriorantes, podendo afetar leites, queijos, carnes vermelhas, pescados e outros frutos do mar, além de vegetais. Algumas espécies deste grupo podem produzir diversos compostos voláteis e enzimas pécticas capazes de destruir os tecidos dos vegetais, ocasionando por exemplo a podridão em peras (BAYLIS, 2006). Apesar dos esforços em reduzir as perdas de alimentos por deterioração microbiana, o desafio ainda é grande. Recentemente, uma pesquisa realizada com 164 produtores e engarrafadores de sucos (membros de associações deste tipo de produtos nos Estados Unidos e na Europa) revelou que ao menos anualmente eles descartam quantidade expressiva de ingredientes ou produtos finais devido à perda de qualidade, indicando a necessidade de melhores opções para a detecção e inativação dos micro-organismos deteriorantes, assim como otimização dos procedimentos de sanitização (SNYDER; WOROBO, 2018).

A microbiota das frutas é bastante influenciada pela contaminação inicial no campo, principalmente através do solo e águas de irrigação (PARAMITHIOTIS; DROSINOS; SKANDAMIS, 2017), podendo incluir micro-organismos patogênicos. Esses contaminantes microbianos podem estar presentes na casca e na polpa da fruta, podendo migrarem de um lugar a outro através da internalização (REZENDE et al., 2016) e assim contaminar o maquinário e o produto final durante o processamento.

Durante a fabricação, a carga microbiana proveniente das matérias-primas ou da contaminação através do equipamento/meio ambiente pode permanecer na polpa/suco antes da etapa de pasteurização (RAMOS et al., 2017) e somente tratamentos térmicos ou alternativos (não-térmicos) são capazes de reduzir e controlar essa carga microbiológica. Neste estudo, os 30 lotes de fabricação avaliados em cada produto para verificar a carga residual de enterobactérias e coliformes totais depois da pasteurização resultaram em ausência (<10 UFC $\mathrm{g}^{-1}$ ) destes micro-organismos. Algumas bactérias patogênicas pertencentes ao grupo de enterobactérias e coliformes totais, como Salmonella enteritidis e E. coli O157: $\mathrm{H} 7$, podem sobreviver aos fatores intrínsecos dos sucos/polpas de frutas ácidas; no entanto, tratamentos térmicos superiores a $71,1^{\circ} \mathrm{C}$ por 3 segundos aplicados a este grupo de alimentos com $\mathrm{pH}$ menor do que 3,9 são suficientes para garantir uma redução mínima de 5 Log destes micro-organismos (MAZZOTTA, 2001). 

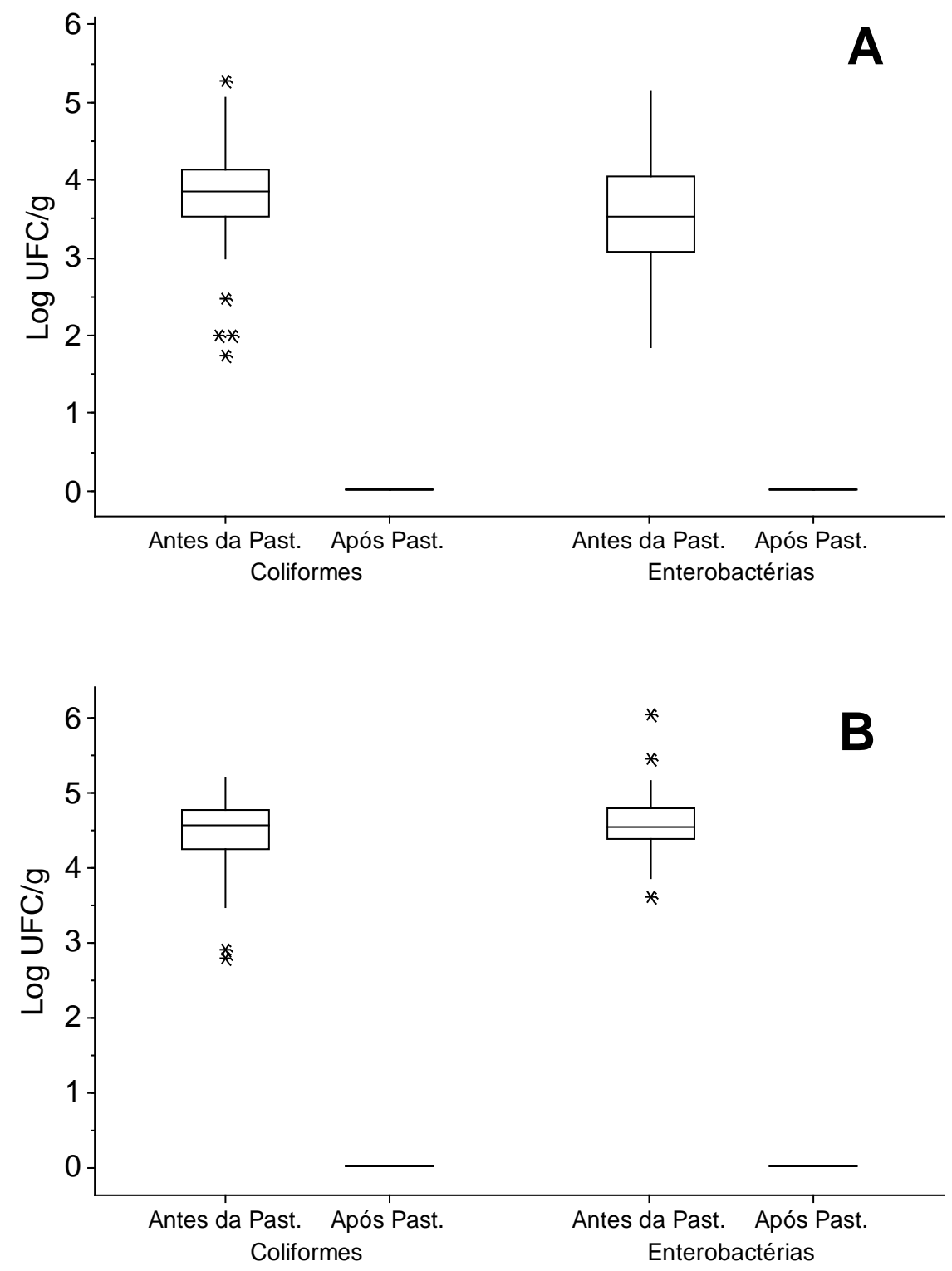

Figura 5. Diagrama de caixas comparativo das contagens microbiológicas de coliformes totais e de enterobactérias, antes e após pasteurização, em polpa de morango (A) e em suco de maracujá (B) industrializados. Past: Pasteurização.

Considerando o valor das medianas, reduções de 3,52 e 4,54 Log UFC g $^{-1}$ nas contagens de enterobacterias em PM e em SM, respectivamente, foram mostradas neste estudo (Figura 5). Apesar de encontrar contagens de enterobactérias e coliformes totais superiores a 5 Log nas amostras provenientes da etapa de homogeneização, a pasteurização aplicada pela indústria em pauta reduz e controla esses grupos de micro-organismos. Enterobactérias e coliformes são muito sensíveis aos tratamentos térmicos, principalmente em meio ácido. Assim, por exemplo, no estudo de Ramos, López e Noa (2016), quando foi aplicada a etapa do chapoteo à polpa de camu-camu em nível industrial, não se detectaram contagens de enterobactérias, assegurando uma redução média de 3,65 \pm 0,03 Log UFC $\mathrm{g}^{-1}$ quando comparadas a um processo de extração mecânica convencional. Desta forma, esta 
etapa que aplica calor e ao mesmo tempo melhora as características químicas e sensoriais da polpa, assegura a estabilidade microbiológica.

Através dos diagramas de caixas pode-se observar que não existe diferença marcante entre as contagens de enterobactérias e de coliformes totais nas polpas/sucos sem pasteurizar, confirmando que o processo de pasteurização reduz consideravelmente a carga residual de micro-organismos entéricos até um nível onde eles não podem ser detectados usando a metodologia de contagem por plaqueamento. É importante mencionar que, apesar de existir variabilidade nas contagens individuais de coliformes em SM, em conjunto elas não diferem muito das contagens obtidas para a PM.

Considerando o descrito na pesquisa de Ruby e Ingham (2009), as combinações de tempo e temperatura aplicados no tratamento térmico, e que todas as contagens de micro-organismos indicadores obtidos neste estudo foram positivos para bactérias patogênicas (Salmonella enteritidis ou Escherichia coli 0157:H7), a pasteurização aplicada assegura que os produtos finais cumpram com os padrões de inocuidade estabelecidas para sucos/polpas de frutas (FDA, 2004).

\section{Conclusão}

Apesar de existir diferenças entre as características físico-químicas e nas formas de cultivo das matérias-primas correspondentes, a polpa de morango (PM) e o suco de maracujá (SM) sem pasteurizar não apresentaram grandes diferenças entre as contagens de enterobactérias e coliformes totais num processo industrial. Essas contagens adequaram-se melhor às distribuições de Laplace (coliformes totais em PM e enterobactérias em SM), Normal (enterobactérias em PM) e ExtValueMin (coliformes totais em SM), segundo os critérios estatísticos avaliados. O tratamento térmico aplicado pela indústria em pauta foi eficiente na redução dessa carga de microorganismos em ambos os produtos (PM e SM), inclusive contra valores que excederam os 5 Log (padrão). O SM foi o produto que mais valores fora do padrão apresentou nas contagens de enterobactérias $(11,3 \%)$ e coliformes totais $(9,7 \%)$, no entanto foram reduzidos completamente $\left(<10\right.$ UFC $\left.\mathrm{g}^{-1}\right)$ pela pasteurização. A quantificação desses grupos de micro-organismos antes e depois da pasteurização permitiu à equipe de garantia de qualidade da fábrica validar que o tratamento térmico aplicado pela indústria processadora desses produtos (sucos/polpas) assegura uma estabilidade microbiológica em termos de segurança alimentar.

\section{Referências}

ARYAL, G.R. Study of Laplace and related probability distributions and their applications. 2006. 97 p. Dissertation (Doctor of Philosophy)-Department of Mathematics, College of Arts and Sciences, University of South Florida, Florida, 2006.

BAYLIS, C.L. Enterobacteriaceae. In: BLACKBURN, C de W. (ed). Food spoilage microorganisms. Cambridge: Woodhead Publishing Limited, 2006. p. 624-667.

BAYLIS, C. et al. The Enterobacteriaceae and their significance to the food industry. ILSI Europe Report Series. Brussels: ILSI Europe, 2011. 52 p. Disponível em: <https://ilsi.eu/publication/the-enterobacteriaceae-and-their-significance-to-thefood-industry/>. Acesso 28 dez. 2020.

BEVILACQUA, A. et al. Nonthermal technologies for fruit and vegetables juices and beverages: Overview and advances. Comprehensive Reviews in Food Science and Food Safety, v.17, n.1, p. 2-62, jan. 2018. https://doi.org/10.1111/1541-4337.12299. 
CABRAL, L.M.C.; FREIRE JÚNIOR, M.; MATTA, V.M. da. Suco de maracujá. In: VENTURINI FILHO, W. G. (coord.). Bebidas não alcoólicas: ciência e tecnologia. São Paulo: Blucher, 2010. v. 2, cap. 16, p. 303-314.

CORRADINI, M.G. et al. Estimating the frequency of high microbial counts in commercial food products using various distribution functions. Journal of Food Protection, v.64, n.5, p. 674-681, maio. 2001. https://doi.org/10.4315/0362-028X64.5.674.

CORRADINI, M.G. et al. Estimating the frequency of future high microbial counts in records with an actual or potential trend or periodicity. Journal of Food Science, v.67, n.4, p. 1278-1285, maio. 2002. https://doi.org/10.1111/j.1365-2621.2002.tb10276.x.

COTON, E; LEGUERINEL, I. Effects of pH. In: BATT, CA; TORTORELLO, ML. (ed.). Encyclopedia of Food Microbiology. 2. ed. London: Academic Press, 2014. v. 1, p. 577-586.

DELBEKE, S. et al. Microbial safety and sanitary quality of strawberry primary production in Belgium: Risk factors for Salmonella and shiga toxin-producing Escherichia coli contamination. Applied and Environmental Microbiology, v.81, n.7, p. 2562-2570, abr. 2015. https://doi.org/10.1128/AEM.03930-14.

FRANCO, B.D.G.M.; LANDGRAF, M. Microbiologia dos alimentos. São Paulo: Editora Atheneu, 2008. 182 p.

Food and Agriculture Organization of the United Nations/World Health Organization (FAO/WHO). Statistical aspects of microbiological criteria related to foods. A risk managers guide. Microbiological Risk Assessments Series, $\mathbf{n}^{\circ} \mathbf{2 4}$. Rome: FAO/WHO, 2016. 120 p.

GOH, E.L.C. et al. Baroprotective effect of increased solute concentrations on yeast and moulds during high pressure processing. Innovative Food Science \& Emerging

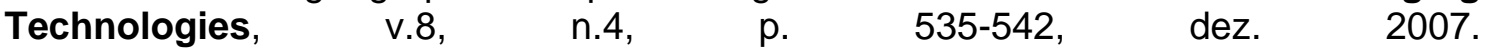
https://doi.org/10.1016/j.ifset.2007.04.004.

INTERNATIONAL ORGANIZATION FOR STANDARDIZATION (ISO). ISO 750: Fruit and vegetable products - Determination of titratable acidity. Geneva, 1998.

INTERNATIONAL ORGANIZATION FOR STANDARDIZATION (ISO). ISO 1842: Fruit and vegetable products - Determination of $\mathrm{pH}$. Geneva, 1991.

INTERNATIONAL ORGANIZATION FOR STANDARDIZATION (ISO). ISO 2173: Fruit and vegetable products - Determination of soluble solids - Refractometric method. Geneva, 2003.

INTERNATIONAL ORGANIZATION FOR STANDARDIZATION (ISO). ISO 21528-2: Microbiology of food and animal feeding stuffs - Horizontal methods for the detection and enumeration of Enterobacteriaceae - Part 2: Colony-count method. Geneva, 2004. JOHANNESSEN, G.S. et al. Occurrence of Escherichia coli, Campylobacter, Salmonella and shiga-toxin producing $E$. coli in Norwegian primary strawberry production. International Journal of Environmental Research and Public Health, v.12, n.6, p. 6919-6932, 2015. https://doi.org/10.3390/ijerph120606919. 
JONGENBURGER, I. et al. Impact of microbial distributions on food safety I. Factors influencing microbial distributions and modelling aspects. Food Control, v.26, n.2, p. 601-609, aug. 2012. https://doi.org/10.1016/j.foodcont.2012.02.004.

KILSBY, D.C.; PUGH, M.E. The relevance of the distribution of micro-organisms within batches of food to the control of microbiological hazards from foods. Journal of Applied Bacteriology, v.51, n.2, p. 345-354, Oct. 1981. https://doi.org/10.1111/j.13652672.1981.tb01251.x.

KORNACKI, JL; JOHNSON, JL. Enterobacteriaceae, coliforms, and Escherichia coli as quality and safety indicators. In: DOWNES, F.P.; ITO, K. (ed). Compendium of methods for the microbiological examination of foods. 4. ed. Washington, DC: American Public Health Association (APHA), 2001. p. 69-82. Disponível em: $<$ https://ajph.aphapublications.org/doi/abs/10.2105/MBEF.0222.014>. Acesso $28 \mathrm{dez}$. 2020.

MAZZOTTA, A. Thermal inactivation of stationary-phase and acid-adapted Escherichia coli O157:H7, Salmonella, and Listeria monocytogenes in fruit juices. Journal of Food Protection, v.64, n.3, p. 315-320, mar. 2001. https://doi.org/10.4315/0362-028x64.3.315.

MERCURI, A.J. et al. Relation of Enterobacteriaceae counts to Salmonella contamination of market broilers. Journal of Food Protection, v.41, n.6, p. 427-428, jun. 1978. https://doi.org/10.4315/0362-028X-41.6.427.

MISKIMIN, D.K. et al. Relationships between indicator organisms and specific pathogens in potentially hazardous foods. Journal of Food Science, v.41, n.5, p. 1001-1006, set. 1976. https://doi.org/10.1111/j.1365-2621.1976.tb14376.x.

ORELLANA, L.E. et al. Non-thermal methods for food preservation. In: JUNEJA, V.; DWIVEDI, HP; SOFOS, JN. (ed). Microbial Control and Food Preservation. Theory and Practice. New York: Springer Science + Business Media, LLC, 2017. p. 299-326. https://doi.org/10.1007/978-1-4939-7556-3.

OYARZÁBAL, O.A.; NOGUEIRA, M.C.L.; GOMBAS, D.E. Survival of Escherichia coli O157:H7, Listeria monocytogenes, and Salmonella in juices concentrates. Journal of Food Protection, v.66, n.9, p. 1595-1598, set. 2003. https://doi.org/10.4315/0362028x-66.9.1595.

PARAMITHIOTIS, S; DROSINOS, EH; SKANDAMIS, PN. Microbial ecology of fruits and fruit-based products. In: SANT'ANA, AS. (ed). Quantitative microbiology in food processing: modeling the microbial ecology. Chichester, West Sussex: John Wiley \& Sons, Ltd., 2017. p. 358-381.

PARISH, M.E. Coliforms, Escherichia coli and Salmonella serovars associated with a citrus-processing facility implicated in a Salmonellosis outbreak. Journal of Food Protection, v.61, n.3, p. 280-284, mar. 1998. https://doi.org/10.4315/0362-028X61.3.280

PELEG, M. Interpretation of the irregularly fluctuating microbial counts in commercial dairy products. International Dairy Journal, v.12, n.2-3, p. 255-262, 2002. https://doi.org/10.1016/S0958-6946(01)00103-0. 
RAMOS, F.G.; LÓPEZ, B.C.; NOA, L.A. Efecto del "Chapoteo" sobre la carga microbiológica de enterobacterias y coliformes totales durante la fabricación de pulpa de camu camu. Revista Vitae, v.23, supl.2, p. S135-S136, set. 2016.

RAMOS, F.G. et al. Comportamento dos micro-organismos indicadores frente ao Chapoteo na produção de polpa de camu-camu. Revista Higiene Alimentar, v.31, n.270/271, p. 109-113, jul/ago. 2017. Disponível em: $<$ https://pesquisa.bvsalud.org/portal/resource/pt/biblio-848951?lang=es>. Acesso 28 dez. 2020.

REZENDE, A.C.B. et al. Incidence and growth of Salmonella enterica on the peel and pulp of avocado (Persea americana) and custard apple (Annona squamosa). International Journal of Food Microbiology, v.235, p. 10-16, out. 2016. https://doi.org/10.1016/j.ijfoodmicro.2016.06.034.

RODRIGUES, E.C.N.; RIBEIRO, S.C.A.; da SILVA, F.L. Não padronização de procedimentos operacionais em agroindústria familiar de polpa de frutas e seus efeitos na renda e satisfação dos associados. Observatorio de la Economía Latinoamericana, v.208, p. 1-19, mar. 2015. Disponível em: <https://ideas.repec.org/a/erv/observ/y2015i20811.html>. Acesso 28 dez. 2020.

RUBY, J.R.; INGHAM, S.C. Use of Enterobacteriaceae analysis results for predicting absence of Salmonella serovars on beef carcasses. Journal of Food Protection, v.72, n.2, p. 260-266, fev. 2009. https://doi.org/10.4315/0362-028x-72.2.260.

SALOMÃO, B.C.M. Pathogens and spoilage microorganisms in fruit juice. In: RAJAURIA, G; TIWARI, BK. (ed). Fruit juices: extraction, composition, quality and analysis. Oxford: Academic Press, 2018. p. 291-308.

SLONGO, A.P.; MIORELLI, S.; ARAGÃO, G.M.F. Influência de diferentes fatores na termorresistência de Neosartorya fischeri em suco de mamão. Alimentos e Nutrição, Araraquara, v.16, n.4, p. 377-387, out/dez. 2005. Disponível em: <http://200.145.71.150/seer/index.php/alimentos/article/viewArticle/498>. Acesso 28 dez. 2020.

SNYDER, A.B.; WOROBO, R.W. The incidence and impact of microbial spoilage in the production of fruit and vegetable juices as reported by juice manufacturers. Food Control, v.85, p. 144-150, mar. 2018. https://doi.org/10.1016/j.foodcont.2017.09.025.

STRAWN, L.K.; SCHNEIDER, K.R.; DANYLUK, M.D. Microbial safety of tropical fruits. Critical Reviews in Food Science and Nutrition, v.51, n.2, p. 132-145, fev. 2011. https://doi.org/10.1080/10408390903502864.

TRIBST, A.A.L.; SANT'ANA, A.S.; MASSAGUER, P.R. Review: Microbiological quality and safety of fruit juices - past, present and future perspectives. Critical Reviews in $\begin{array}{lllll}\text { Microbiology, } & \text { v.35, } & \text { n.4, } & \text { p. } & 310-339,\end{array}$ https://doi.org/10.3109/10408410903241428.

U.S. FOOD AND DRUG ADMINISTRATION. Guidance for industry: juice HACCP hazards and controls guidance first edition. Silver Spring, 2004. Disponível em: $<$ https://www.fda.gov/Food/GuidanceRegulation/GuidanceDocumentsRegulatorylnform ation/Juice/ucm072557.htm>. Acesso em: 30 dez. 2017. 
VOJDANI, J.D.; BEUCHAT, L.R.; TAUXE, R.V. Juice-associated outbreaks of human illness in the United States, 1995 through 2005. Journal of Food Protection, v.71, n.2, p. 356-364, fev. 2008. https://doi.org/10.4315/0362-028x-71.2.356.

\section{Agradecimentos}

Os autores deste trabalho desejam agradecer à empresa SELVA INDUSTRIAL S.A., quem permitiu obter as amostras e realizar as análises para o estudo correspondente.

\section{Autores}

Félix Giovani Ramos Guerrero ${ }^{1, *}$, Rosane da Silva Rodrigues $^{2}$

1. Curso de Pós-Graduação Lato Sensu em Ciência dos Alimentos, Universidade Federal de Pelotas, Pelotas, RS, Brasil; Centro Latinoamericano de Enseñanza e Investigación de Bacteriología Alimentaria (CLEIBA), Facultad de Farmacia y Bioquímica, Universidad Nacional Mayor de San Marcos, Jr. Puno N 1002, Lima 1, Lima, Perú.

2. Centro de Ciências Químicas, Farmacêuticas e de Alimentos, Universidade Federal de Pelotas, Caixa postal 354, Cep 96010.900, Pelotas, RS, Brasil.

* Autor para correspondência: felix.ramos@unmsm.edu.pe 